\title{
Changes in Sediment Concentration on Grassland Slope with Optimized Vegetation Characteristics
}

\author{
Dongdong Wang ${ }^{1}$ \\ ${ }^{1}$ College of Resources, Environment and Planning, Dezhou University
}

July 3,2020

\begin{abstract}
The artificial simulated rainfall test method is used to deeply analyze the mechanism of the change of sediment concentration on the grassland slope .Under the experimental condition, the results show the following. 1). The addition of root volume can increase the accuracy of the expression of the sediment concentration variability and reduction of sediment concentration by $0.5 \%$ and $1.12 \%$, respectively; 2). The relationship between the vegetation characteristics and the sediment concentration on the grassland slope is best expressed by the coverage and root volume; 3). The slope plays a larger role than the rain intensity in the change of sediment concentration on grassland slopes .
\end{abstract}

\section{Hosted file}

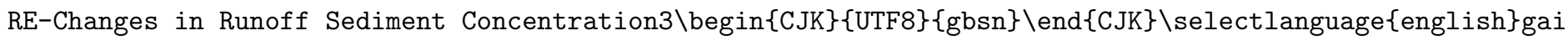
available at https://authorea.com/users/333569/articles/465756-changes-in-sedimentconcentration-on-grassland-slope-with-optimized-vegetation-characteristics

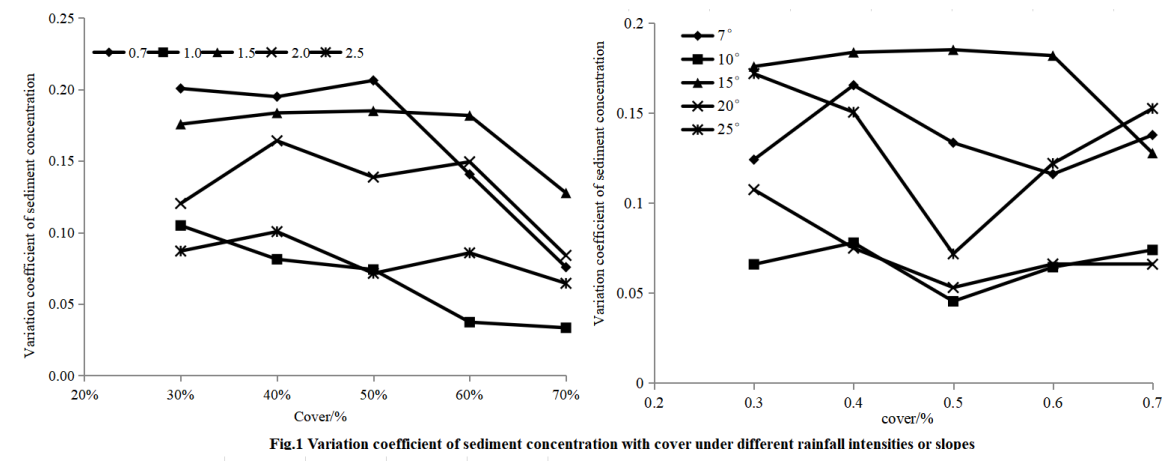



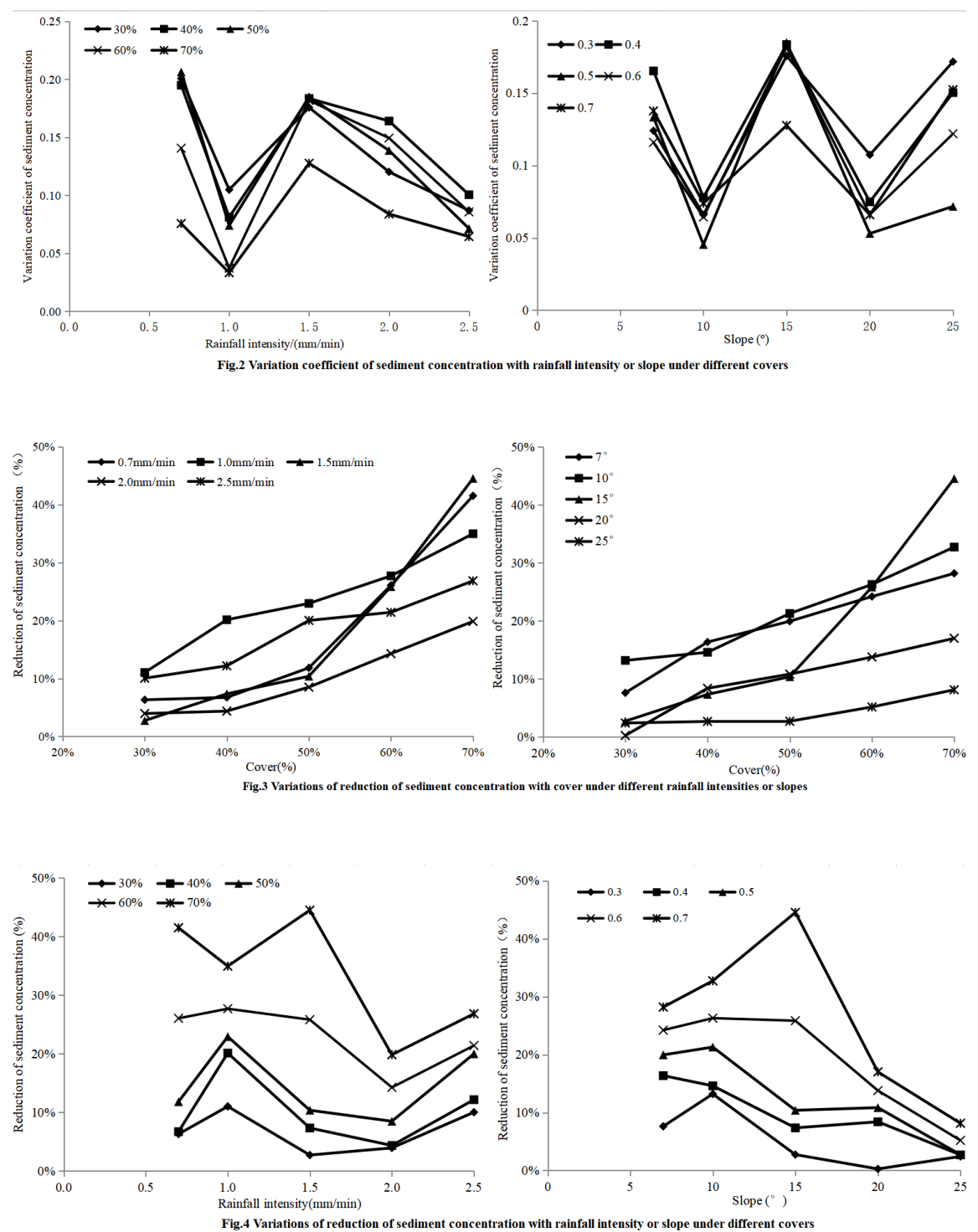